\title{
Right Colonic Diverticulitis
}

\author{
In Kyu Lee \\ Department of Surgery, The Catholic University of Korea School of Medicine, Seoul, Korea
}

Although right colonic diverticultis (RCD) has been reported to be a rare disease in Western countries, RCD is a common diagnosis, with an incidence per 2.9-17 case of appendicitis, in Korea. Many Western studies have reported that it is difficult to differentiate the presenting symptoms of RCD from those of appendicitis before surgery because the signs and symptoms are similar. However, performing a computed tomography scan after the application of the diagnostic criteria for RCD has increased the preoperative RCD diagnostic rate. Treatment strategies have been difficult to define for this condition due to its low preoperative diagnosis rate. However, recent reports have shown that conservative medical treatment of uncomplicated RCD can be recommended and that such treatment is effective due to the benign and self-limited natural history of RCD. Therefore, in this review, we discuss the controversies surrounding RCD management.

Keywords: Diverticulitis; Right Colon; Diagnosis

\section{INTRODUCTION}

Right colonic diverticulitis (RCD) is a common disease, especially in Asia, and it does not have a clear treatment strategy because of difficult pre-operative diagnosis. However, diagnostic criteria using symptoms that are distinguishable from appendicitis and the use of universalized computed tomography (CT) are increasing pre-operative diagnosis of RCD $[1,2]$. Western countries in the past insisted on an aggressive resection because of frequent relapse after symptomatic treatment and necessary surgical treatment [3-5]. However, current research supports symptomatic treatment because clinical findings are not severe and the disease itself is self-limited [6-8]. This article discusses the epidemiology, symptoms, diagnosis, treatment, and prognosis of RCD.

Received: May 28, 2010 Accepted: June 27, 2010

Correspondence to: In Kyu Lee, M.D.

Department of Surgery, Yeouido St. Mary's Hospital, The Catholic University of Korea School of Medicine, 62 Yeouido-dong, Yeongdeungpo-gu, Seoul 150-713, Korea

Tel: +82-2-3779-2235, Fax: +82-2-786-0802

E-mail: cmcgslee@catholic.ac.kr

(C) 2010 The Korean Society of Coloproctology

This is an open-access article distributed under the terms of the Creative Commons Attribution NonCommercial License (http://creativecommons.org/licenses/by-nc/3.0) which permits unrestricted noncommercial use, distribution, and reproduction in any medium, provided the original work is properly cited.

\section{EPIDEMIOLOGY OF RCD}

Although RCD has been reported to be a rare disease in Western countries, it is very common in Korea, with an incidence per 2.9-17 cases of appendicitis [1, 2, 8-13]. Also, although the diagnostic rate has been low in the past, the use of universalized abdominal CT scans and improvements in diagnostic criteria have increased the diagnostic rate to $85.7 \%[1,2,8]$. RCD is especially common among males (2-3. 2:1) in their relatively early years (32-53.1) $[1,2,6,8,14]$. On the other hand, left colonic diverticulitis (LCD) is more common among females (based on autopsy research), with $40-50 \%$ being over 75 years old, and $13 \%$ being under 54 years old, thus showing a greater frequency among aging patients [15]. The frequency of right colonic diverticula among Caucasians is reported to be $1.5 \%$ whereas the frequency among Asians is reported to be 55-70\%. Therefore, RCD occurs more frequently in Asians than Caucasians because of innate characteristics, and RCD occurs more frequently than LCD in males [16-19].

\section{SYMPTOMS OF RCD}

It is difficult to distinguish RCD from appendicitis because of their similar signs and symptoms at time of presentation, so preoperative diagnosis is often difficult. However, the clinical characteristics of RCD, such as relatively long right lower abdominal pain, less systematic inflammatory response, less nau- 
sea and vomiting, and ache starting from the right lower abdomen, have been reported to be different from those of appendicitis [10-13]. In our previous retrospective study of 90 patients with RCD, the preoperative positive diagnosis rate was $43 \%$, which is higher than in other previous reports [2]. This was because a diagnosis of RCD was made with a CT scan when there were symptoms and signs, such as right lower quadrant pain without migration of the pain and leukocytosis, or if the patients presented with diarrhea and no sign of systemic toxicity, plus a lateralized right lower quadrant pain that is uncommon in patients with appendicitis. The clinical findings from which RCD could be diagnosed preoperatively in our previous study were selected from the major criteria. However, with the minor criteria, the clinical findings by which RCD was differentiated from appendicitis were symptoms common to other diseases.

When these criteria were applied, the sensitivity was $11 / 13$ (84.6\%), and the specificity was 59/87 (67.8\%) (Table 1) [1]. Cases without migrating abdominal pain and with normal white blood cell count $<10,000 / \mathrm{mm}^{3}$ showed significant differences in these diagnostic criteria when compared with cases of appendicitis.

The above results agree with the results of other RCD research, which showed less pain migration from the upper to the right lower abdomen and pain starting from the right lower abdomen $[1,2,12,13]$. The results also agreed with the results from the author's previous research where 64 patients $(71.1 \%)$ had pain starting from the right lower abdomen [20]. According to other results from the author's research, when the white blood cell count was less than 10,000, $86 \%$ of the patients did not have appendicitis [20]. Other researchers have reported that among RCD cases, 29 patients $(32.2 \%)$ had white blood cell count less than or equal to $10,000 / \mathrm{mm}^{3}$, and $33(36.7 \%)$ had neutrophil less than 70\% [2]. Based on these results, RCD is difficult to differentiate from appendicitis in its early stages because of their symptoms being similar, but less systematic inflammation reaction might be a differentiating category. Cases with severe diverticulitis show severe systematic inflammation, but misdiagnosis is prevented by many studies used to differentiate this condition from other diseases caused by aggravated symptoms. In many cases of RCD, the pain region is more lateral and above that of appendicitis. Thirty eight point five percent of the patients with RCD and $18.4 \%$ of the patients with appendicitis had pain regions that were not the right lower abdomen, but these differences are not statistically significant [1]. The first minor criterion of not having nausea and vomiting was reported in other research to be $11-35.4 \%$ of RCD patients and $32.1-75 \%$ of appendicitis patients [9, 10, 14, 21-23]. Through a retrospective study, only 17 patients (18.9\%) showed nausea, and 5 patients (5.6\%) showed vomiting [2]. In a prospective study, only 1 out of 13 patients with RCD had nausea and vomiting; showing a significant difference from patients with appendicitis $(\mathrm{P}<0.001)[1]$. Because other diseases do not have such symptoms, it might be meaningful to include this parameter as a minor criterion. However, these symptoms might not occur in other diseases, they may be significant in differentiating RCD from appendicitis as a minor criterion. Reoccurring abdominal pain was found in $30.8 \%$ of the RCD patients and in $11.8 \%$ of the appendicitis patients. Although this result was not statistically significant $(P=0.093)$, it may be useful because cases with RCD tend to show reoccurring pain [1].

\section{RCD DIAGNOSIS}

The sensitivity and the specificity are reported to be as much as $98 \%$ in CT scans for RCD [22]. Criteria for diagnosing RCD via $\mathrm{CT}$ scans are thickening of the large-intestine wall $(<5 \mathrm{~mm})$, pericolonic fat infiltration, pericolonic abscesses, intramural air bubbles, a sinus tract, and extraluminal air [22-24]. From our previous studies, all patients with RCD showed large-intestine wall thickening and pericolonic fat infiltration, 90\% had ileocolic lymphadenopathy, and $60 \%$ had diverticula and a normal appendix [1]. CT scans in left sided diverticulitis cases are being reported to have sensitivities of $91-95 \%$ and specificities of $72-77 \%$ [24]. However, there are reports mentioning the difficulty of differentiating RCD from colon cancer

Table 1. Comparison of diagnostic criteria between RCD and appendicitis

\begin{tabular}{|c|c|c|c|c|c|c|}
\hline \multirow{2}{*}{\multicolumn{2}{|c|}{ Diagnostic criteria }} & \multicolumn{2}{|c|}{ Diverticulitis $(n=13)$} & \multicolumn{2}{|c|}{ Appendicitis $(n=76)$} & \multirow{2}{*}{$\begin{array}{r}\text { P-value } \\
0.027\end{array}$} \\
\hline & & \multirow{2}{*}{$\begin{array}{l}\text { Positive } \\
6(46.2) \\
7(53.8) \\
5(38.5) \\
1(7.7)\end{array}$} & \multirow{2}{*}{$\begin{array}{r}\text { Negative } \\
7(53.8) \\
6(46.2) \\
8(61.5) \\
12(92.3)\end{array}$} & \multirow{2}{*}{$\begin{array}{c}\text { Positive } \\
14(18.4) \\
16(21.1) \\
14(18.4) \\
0(0)\end{array}$} & \multirow{2}{*}{$\begin{array}{l}\text { Negative } \\
62(81.6) \\
60(78.9) \\
62(81.6) \\
76(100)\end{array}$} & \\
\hline Major & $\begin{array}{l}\text { No pain migration } \\
\text { Leukocyte count }<10,000 / \mathrm{mm}^{3} \\
\text { Lateralized abdominal pain } \\
\text { History of RCD }\end{array}$ & & & & & $\begin{array}{l}0.027 \\
0.013 \\
0.103 \\
0.146\end{array}$ \\
\hline Minor & $\begin{array}{l}\text { History of the same pain } \\
\text { No N/N symptom } \\
\text { History of D/C } \\
\text { Abdominal pain over } 7 \text { days }\end{array}$ & $\begin{aligned} 4 & (30.8) \\
12 & (92.3) \\
2 & (15.4) \\
0 & (0)\end{aligned}$ & $\begin{aligned} 9 & (69.2) \\
1 & (7.7) \\
11 & (84.6) \\
1 & (100)\end{aligned}$ & $\begin{aligned} 9 & (11.8) \\
21 & (27.6) \\
16 & (21.1) \\
2 & (2.6)\end{aligned}$ & $\begin{array}{l}67(88.2) \\
55(72.4) \\
60(78.9) \\
74(97.4)\end{array}$ & $\begin{array}{l}0.093 \\
0.000 \\
1.000 \\
1.000\end{array}$ \\
\hline
\end{tabular}

Values are presented as number (\%).

$\mathrm{RCD}$, right colonic diverticulum; N/N, nausea or vomiting; $\mathrm{D} / \mathrm{C}$, diarrhea or constipation. 
[1]. Although some reports claim that inflammatory diverticula and a preserved enhancement pattern of a thickened colon wall can be used as differentiating factors, colonoscopy or a barium enema (BE) is necessary for accurate differentiation. A retrospective study showed that $62.2 \%$ of the RCD patients had 2 or more diverticula [2], and a prospective study showed that more than $66.7 \%$ were multicentric [1]. These results convey that a BE should be performed after management because there were multiple right colonic diverticula in many patients and an accurate diagnosis and a differential diagnosis are needed. Also, the fact that diverticula are multicentric once more signifies the importance of preoperative diagnosis.

\section{TREATMENT AND PROGNOSIS OF RCD}

In RCD patients without complications, most doctors report that symptomatic treatment by using antibiotics is possible. However, the preoperative diagnosis rate is low, so the role of antibiotic treatment is limited $[6,7]$. However, the author's previous research showed that symptomatic treatment is effective when the preoperative diagnosis rate is increased [1]. These results, however, are retrospective results and might have a selection bias in that the treatment was effective on patients with minor symptoms (Fig. 1). In order to remove the bias, a randomized controlled trial is necessary. However, all RCD patients are being treated with symptomatic treatment based on experience. The treatment method is phleboclysis of three types of antibiotics (cephalorprin, aminoglycoside, metronidazole) during hospitalization and oral antibiotic administration for 7 days after discharge. In cases where the patient has pain during outpatient, the period of oral antibiotic administration is extended. Water intake is available when there is tenderness without abdominal pain, and the patient is discharged when symptoms are not exacerbated after digesting porridge. A barium enema is performed 1 month after discharge, and it has been reported that diverticulitis patients with complications lower than type I can be cured without other complications. The relapse rate is only $16.7 \%$, and most cases are cured through symptomatic treatment. Cases needing surgical treatment are successfully cured by surgery without complications after knowing the exact number and location of diverticula [8]. These patients do not show differences in clinical characteristics when compared retrospectively with patients of previous research. There is no difference in the relapse rate, which indicates that symptomatic treatment is a basic treatment for RCD without complications (Fig. 1).

Recent research reported that mesalazine could be used in the treatment for left side diverticulitis because of the theoretical fact that colon diverticulitis has a pathogenesis similar to that for inflammatory enteritis. However, more research is necessary to verify that conclusion because there is no precedent of mesalazine being used in RCD treatment [25].

Surgical treatment is often necessary to confirm cases, relapsed cases or complicated cases. A diverticulectomy and an appendectomy are used as surgical treatment for inflamed diverticula. These methods can be used in patients in whom inflammation is not severe and the area containing the diverticula can be distinguished from the normal surrounding area. Although these methods are widely performed because of fewer complications and less possibility of relapse, the possibility of a malignant tumor and the possibility of a relapse occurring if the RCD is multicentric cannot be disregarded $[1,2,4,9,13,26]$. How-
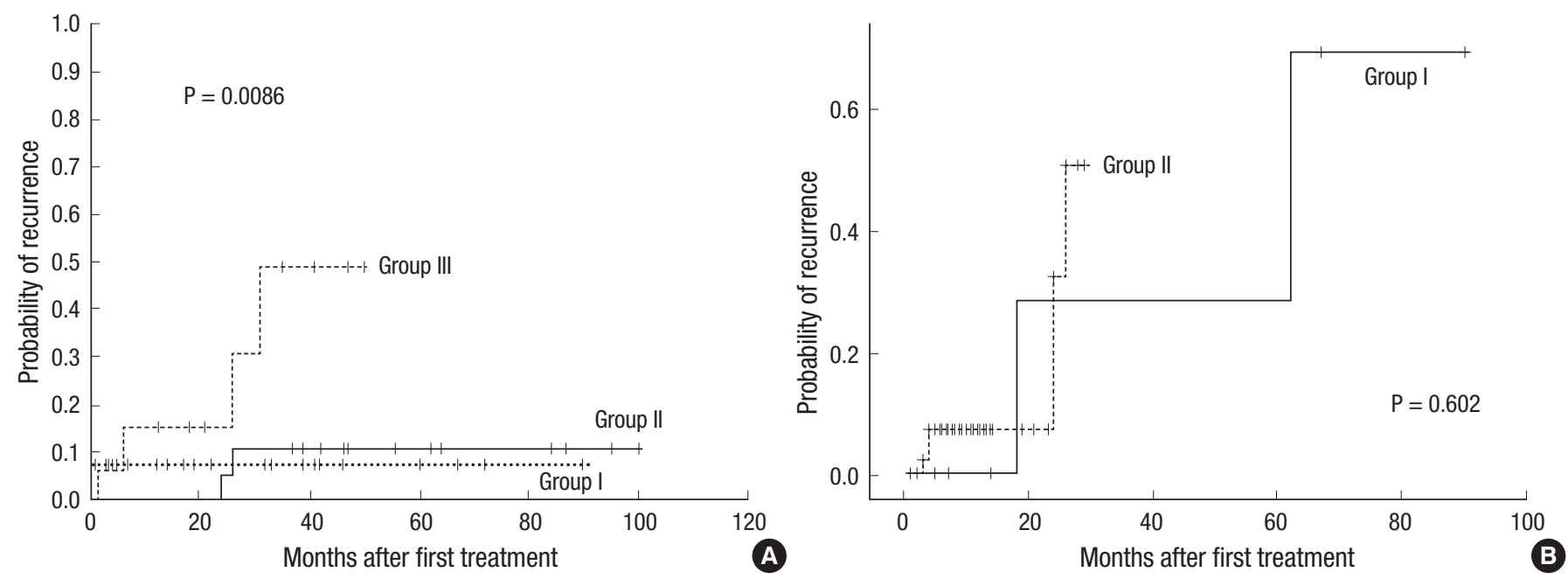

Fig. 1. Probability of recurrence after the first treatment by groups. (A) The Kaplan-Meier estimated recurrence rates for groups I, II, and III were different, and this finding was statistically significant $(\mathrm{P}=0.0086)$ : Group I, conservative medical management; Group II, aggressive resection; Group III, conservative surgical management. (B) The Kaplan-Meier estimated recurrence risk was not significantly different between the retrospective study group (Group I) and the prospective study group (Group II) in conservative medical management $(\mathrm{P}=0.602)$. 
ever, in cases diagnosed during surgery, it is impossible to determine all the locations of the diverticula without inflammation, and the operation is not planned surgery, so there are some risks associated with extensive surgery. Also, the relapse rate is high when only antibiotic treatment is done after an appendectomy [2]. According to our previous study, $4.3 \%$ of the patients who only underwent a diverticulectomy had relapses, and these patients had multicentric diverticula and showed relapses after 24 and 26 months, respectively [2]. Thus, a diverticulectomy has a smaller surgical range, fewer complications, and a similar relapse rate when compared with a right hemicolectomy, so it might be recommended for cases with a single diverticulum or for cases diagnosed during surgery [8].

The second method is ileocecectomy or right hemicolectomy. These methods allow histologically-based diagnoses, and the appropriate cancer surgery is conducted when carcinoma cannot be excluded and recurrence can be prevented [7, 13, 21]. The disadvantage of these procedures is a higher possibility of morbidity and mortality as compared to other surgical procedures; as well as a physiologic change due to the removal of the ileocecal valve. Many researchers have reported an ileocecectomy to be a safe surgical procedure and to be the preferred treatment for preventing relapse with only minor complications $[6,7,9,10,21,27]$. In our case, three right hemicolectomies and five laparoscopic right hemicolectomies were done without major complications. A right chemicolectomy is performed when patients have complicating diverticulitis and it is impossible to do only a diverticulectomy and when differentiation from a malignant tumor cannot be confirmed [8].

After the development of laparoscopic surgery, differentiation between RCD and appendicitis became easier through laparoscopy. Now through the advanced techniques of laparoscopic surgery, diverticulectomy, ileocecectomy and right hemicolectomy are being performed as well $[2,8,28]$. In the past, there were no data comparing open and laparoscopic surgery for RCD patients. According to one report about left colon diverticulitis, laparoscopic surgery had a longer operation time but a shorter hospitalization period [29]. In my case, there were no statistical differences in operation time, hospitalization period and relapse rate between open and laparoscopic surgery [8].

\section{CONCLUSION}

RCD is a common disease in South Korea, and an accurate diagnosis is needed to avoid an unnecessary appendectomy. As one of the treatment methods, a diverticulectomy is recommended because it has a low relapse rate and fewer complications when uncomplicating RCD is found during surgery. However, a right hemicolectomy should be performed in cases with multicentric diverticulitis, severe complications, and indistinguishable status. In addition, laparoscopic surgery is a safe and effective treatment method with a similar hospitalization period and similar relapse and complication rates, despite its having a longer operating time. Symptomatic treatment using antibiotics is only appropriate for uncomplicating cases that have been accurately diagnosed.

\section{CONFLICT OF INTEREST}

No potential conflict of interest relevant to this article was reported.

\section{REFERENCES}

1. Lee IK, Jung SE, Gorden DL, Lee YS, Jung DY, Oh ST, et al. The diagnostic criteria for right colonic diverticulitis: prospective evaluation of 100 patients. Int J Colorectal Dis 2008;23:1151-7.

2. Lee IK, Kim SH, Lee YS, Kim HJ, Lee SK, Kang WK, et al. Diverticulitis of the right colon: tips for preoperative diagnosis and treatment strategy. J Korean Soc Coloproctol 2007;23:223-31.

3. Fang JF, Chen RJ, Lin BC, Hsu YB, Kao JL, Chen MF. Aggressive resection is indicated for cecal diverticulitis. Am J Surg 2003;185: 135-40.

4. Ngoi SS, Chia J, Goh MY, Sim E, Rauff A. Surgical management of right colon diverticulitis. Dis Colon Rectum 1992;35:799-802.

5. Harada RN, Whelan TJ Jr. Surgical management of cecal diverticulitis. Am J Surg 1993;166:666-9.

6. Lo CY, Chu KW. Acute diverticulitis of the right colon. Am J Surg 1996;171:244-6.

7. Oudenhoven LF, Koumans RK, Puylaert JB. Right colonic diverticulitis: US and CT findings--new insights about frequency and natural history. Radiology 1998;208:611-8.

8. Lee IK, Lee YS, Kim SJ, Gorden DL, Won DY, Kim HJ, et al. Laparoscopic and open surgery for right colonic diverticulitis. Am Surg 2010;76:486-91.

9. Park JK, Sung JK, Choi SH, Yun SS, Lee S. Clinical analysis of right colon diverticulitis. J Korean Surg Soc 2003;64:44-8.

10. Law WL, Lo CY, Chu KW. Emergency surgery for colonic diverticulitis: differences between right-sided and left-sided lesions. Int J Colorectal Dis 2001;16:280-4.

11. Shyung LR, Lin SC, Shih SC, Kao CR, Chou SY. Decision making in right-sided diverticulitis. World J Gastroenterol 2003;9: 606-8.

12. Chen SC, Chang KJ, Wei TC, Yu SC, Wang SM. Can cecal diverticulitis be differentiated from acute appendicitis? J Formos Med Assoc 1994;93:263-5.

13. Birnbaum BA, Wilson SR. Appendicitis at the millennium. Radiology 2000;215:337-48.

14. Lee EK, Kim H, Son BH, Han WK. Difference in clinical features between appendicitis and right-sided colonic diverticulitis on initial diagnosis. J Korean Soc Coloproctol 2005;21:201-6.

15. Commane DM, Arasaradnam RP, Mills S, Mathers JC, Bradburn M. Diet, ageing and genetic factors in the pathogenesis of diverticular disease. World J Gastroenterol 2009;15:2479-88. 
16. Schuler JG, Bayley J. Diverticulitis of the cecum. Surg Gynecol Obstet 1983;156:743-8.

17. Chia JG, Wilde CC, Ngoi SS, Goh PM, Ong CL. Trends of diverticular disease of the large bowel in a newly developed country. Dis Colon Rectum 1991;34:498-501.

18. Chan CC, Lo KK, Chung EC, Lo SS, Hon TY. Colonic diverticulosis in Hong Kong: distribution pattern and clinical significance. Clin Radiol 1998;53:842-4.

19. Yap I, Hoe J. A radiological survey of diverticulosis in Singapore. Singapore Med J 1991;32:218-20.

20. Lee IK, Sung BH. The Diagnostic value of laboratory tests in acute appendicitis. J Korean Surg Soc 2004;66:42-5.

21. Lane JS, Sarkar R, Schmit PJ, Chandler CF, Thompson JE Jr. Surgical approach to cecal diverticulitis. J Am Coll Surg 1999;188: 629-34.

22. Reid MR, Poer DH, Merrell P. A statistical study of 2,921 cases of appendicitis. JAMA 1936;106:665-9.

23. Kozar RA, Roslyn JJ. The appendix. In: Schwartz SI, editor. Prin- ciples of surgery. 7th ed. New York: McGraw-Hill, Health Professions Division; 1999. pp. 1383-94.

24. Kang JY, Melville D, Maxwell JD. Epidemiology and management of diverticular disease of the colon. Drugs Aging 2004;21:211-28.

25. Floch MH, White JA. Management of diverticular disease is changing. World J Gastroenterol 2006;12:3225-8.

26. Kaufman Z, Shpitz B, Reina A, Dinbar A. Cecal diverticulitis presented as a cecal tumor. Am Surg 1990;56:675-7.

27. Yang HR, Huang HH, Wang YC, Hsieh CH, Chung PK, Jeng LB, et al. Management of right colon diverticulitis: a 10-year experience. World J Surg 2006;30:1929-34.

28. Rubio PA. Laparoscopic resection of a solitary cecal diverticulum. J Laparoendosc Surg 1994;4:281-5.

29. Purkayastha S, Constantinides VA, Tekkis PP, Athanasiou T, Aziz $\mathrm{O}$, Tilney $\mathrm{H}$, et al. Laparoscopic vs. open surgery for diverticular disease: a meta-analysis of nonrandomized studies. Dis Colon Rectum 2006;49:446-63. 